\title{
Trajetória da privatização do sistema de saúde chileno (1924-2005)
}

\author{
Trajectory of the privatization of the Chilean health system (1924- \\ 2005)
}

Fabián Andrés Moraga Cortés', Thereza Christina Bahia Coelho', Clara Aleida Prada Sanabria1

DOI: $10.1590 / 0103-1104202012520$

RESUMO O objetivo do artigo foi analisar a trajetória histórica da conformação público/privada do sistema de saúde chileno, entre 1924 e 2005. Procurou-se situar suas principais reformas, seus atores-chave e seu contexto sociopolítico. Empregou-se a revisão integrativa de literatura como método de obtenção das informações. Entre os achados, destaca-se a reconversão do sistema, que até a metade do século XX foi um caso pioneiro na América Latina, por ter integrado as diferentes instituições em um órgão único nacional, que dirigiu as políticas de saúde sob os princípios da medicina social. Durante e depois da ditadura, o sistema consolidou-se na sua dualidade, na qual o setor público, sendo maioritário, outorga cobertura de saúde aos segmentos que não são rentáveis para as empresas de seguros privados. Outro achado diz respeito à continuidade desta matriz ainda durante governos ditos de centro-esquerda, o que mostra a profundidade das transformações impostas pela ditadura. Esclarecer os detalhes desta estratégia privatizadora é útil para o Brasil, visto o atual contexto de desmonte dos avanços conseguidos.

PALAVRAS-CHAVE Chile. Privatização. Sistemas de saúde.

\begin{abstract}
The aim of this paper was to analyze the historical trajectory of the public/private formation of the Chilean Health System, between 1924 and 2005. The main reforms, key stakeholders and the sociopolitical context of these reforms were identified. Integrative literature review was used as data collection method. Among the findings, the structural reconversion of the system is emphasized, which until the middle of the 20th century was a pioneer system in Latin America, as it integrated several institutions in just one national entity, which directed the health policies on the Social Medicine principles. During and after the dictatorship, the system was consolidated as a dual system, in which the public sector, being the majority, grants health care coverage to segments of the population that are considered as 'unprofitable' by the private insurance companies. Another result was the continuity of this matrix even during the so-called center-left wing governments, which demonstrates how deep the transformations imposed by the dictatorship have been. To know the details of these privatizing strategies is useful and valuable for Brazil, given the current circumstances of reversal of the hard-won gains made.
\end{abstract}

KEYWORDS Chile. Privatization. Health systems.

1 Universidade Estadual de Feira de Santana (UEFS)

- Feira de Santana (BA),

Brasil.

moraga1989@hotmail.com 


\section{Introdução}

Desde 1924, o Chile estruturou seu sistema de saúde influenciado pelas tendências internacionais; inicialmente, na conformação dos Estados de bem-estar social, e, seguidamente, pelas políticas neoliberais de privatização e mercantilização da saúde e pelas conjunturas políticas internas com projetos de Estado conflitantes. O desenvolvimento deste processo tem sido observado, também, com diferentes níveis e modalidades, nos outros países da América Latina. No século XX, existiram três ondas de reformas dos sistemas de saúde. Nas primeiras décadas, surgiram subsídios e programas sociais destinados à população de baixa renda e pobres, os quais foram estendidos aos grupos operários com a implementação de seguros de saúde contributivos. Após a Segunda Guerra Mundial, foram consolidados os sistemas nacionais de saúde, inspirados na universalização e no princípio de cidadania como direito. Finalmente, os anos 1980 e 1990 caracterizaram-se por uma agenda pós welfare state, claramente neoliberal, com forte predomínio do mercado'.

Laurell ${ }^{2}$ coloca a privatização da saúde como parte das dinâmicas de acumulação do capital. Este processo requer que a saúde seja tratada como mercadoria e que o acesso aos serviços não seja estruturado enquanto direito social, além da necessidade de distinguir atividades rentáveis e não rentáveis. Quanto ao financiamento, as mudanças privatizadoras concretizam-se em esquemas de pré-pagamentos, cuja administração representa boas oportunidades de lucro para as seguradoras privadas. Em relação à prestação, a autora aponta que prestadores privados orientam seus serviços à população rica, visando maximizar utilidades.

O conteúdo da agenda neoliberal incluiu a redefinição do mix público-privado; a separação das funções de financiamento e prestação, com diminuição da participação do Estado e ampliação de seu poder na regulação; a focalização da política social nos mais pobres, que não podem acessar ao mercado da saúde; priorização de serviços básicos e com baixo custo; descentralização da prestação para os âmbitos subnacionais; criação de mecanismos de competição para controlar os custos; e incentivos à privatização dos seguros e serviços médicos ${ }^{3}$. As prescrições da agenda foram reforçadas, especialmente nos anos 1990, pelo Banco Mundial (BM).

Reconhecendo a singularidade dos efeitos das reformas neoliberais, Fleury ${ }^{4}$ descreve três tipologias: o modelo dual chileno, o modelo universal brasileiro e o modelo plural da Colômbia. Primeiramente, o modelo dualista chileno se caracteriza pela conformação de um sistema de seguros compulsórios, no qual o seguro público atua como um subsídio aos seguros privados, pois cobre os setores menos dinâmicos da economia, que são rejeitados pelas seguradoras privadas. Diferentemente, o modelo universalista brasileiro materializou-se no Sistema Único de Saúde (SUS), de cobertura universal, financiamento público e atenção descentralizada. Por último, a reforma colombiana impulsou o subsídio à demanda e a separação de funções, associando o acesso aos serviços à aquisição de seguros que cobrem os serviços estabelecidos em um pacote padronizado, estabelecido pelo nível nacional.

Atualmente, o Chile possui um sistema de saúde estruturado sob essas tendências, de caráter dual, materializado na existência de dois tipos de seguros: o sistema público, dirigido pelo Fondo Nacional de Salud (Fonasa), organizado em uma modalidade de solidariedade social; e o sistema privado, liderado pelas Instituciones de Salud Previsional (Isapre), que oferecem seguros privados de saúde invididualmente ${ }^{\mathbf{5}}$. Segundo Parada ${ }^{6}$, o primeiro constitui uma modalidade solidária de financiamento, pois o acesso aos serviços não depende do valor da contribuição social. Contrariamente, as Isapre estabelecem o valor do plano oferecido segundo o risco e a quantidade de pessoas filiadas por família, constituindo uma modalidade de seguridade não solidária.

No setor público, as fontes dos recursos financeiros são os impostos gerais vindos da 
arrecadação fiscal, as contribuições sociais obrigatórias (7\% do salário) e os copagamentos feitos pelos usuários. Existe desembolso direto para aquisição de medicamentos ou insumos médicos em farmácias particulares. Os recursos das três primeiras fontes são repassados para o Fonasa, que atua como gerenciador e compra os serviços, aos provedores, para os municípios, que administram os dispositivos de atenção primária, e, também, para o Sistema Nacional de Servicios de Salud (SNSS), que coordena a rede de hospitais públicos. Por sua vez, apenas os trabalhadores do mercado formal, fazendo copagamentos, podem acessar à atenção com prestadores privados conveniados.

As fontes do setor privado são os copagamentos, as contribuições sociais obrigatórias e contribuições adicionais. Estas últimas correspondem aos fundos pagos pelos trabalhadores quando o valor do plano de saúde é superior ao valor da contribuição obrigatória. $\mathrm{O}$ valor real da contribuição dos filiados às Isapre foi estimado, como média, para o ano de 2011, em $10 \%$ do salário ${ }^{7}$. Os recursos das três fontes são administrados pelas Isapre, que estabelecem contratos com os prestadores: médicos, clínicas e hospitais particulares.

As fontes possuem diferentes magnitudes. Becerril-Montekio et al. ${ }^{8}$ estabeleceram, para 2003, que os impostos gerais representaram $27 \%$ dos recursos do sistema. Outro estudo 9 atualizou os dados para 2008, estabelecendo a seguinte distribuição: aporte do Estado (21\%), impostos municipais (1\%), contribuições sociais do Fonasa (15\%), contribuições dirigidas ao sistema de acidentes e enfermidades do trabalho (4,6\%), contribuições sociais das Isapre (10,9\%), contribuições adicionais das Isapre (4,8\%) e desembolso direto (40\%).

Por outra parte, estudos estabeleceram as diferenças do gasto per capita. Informações difundidas pelo Ministerio de Salud (Minsal) apontam que, em 2014, os filiados das Isapre tiveram um gasto per capita 2,7 vezes maior, em comparação aos do Fonasa, com uma média de CLP\$ 1.146.336 (USD\$ 1.910) e CLP\$ 411.720 (USD\$ 686), respectivamente ${ }^{10}$. Também se observou que, para 2003, 38\% dos recursos totais que o país tinha disponíveis foram gastos com $21 \%$ da população assegurada pelas Isapre, enquanto $62 \%$ dos recursos, com $79 \%$ das pessoas pertencentes ao Fonasa ${ }^{11}$.

Quanto à cobertura dos dois setores, estatísticas recentes dimensionaram, para 2016, que o Fonasa representou uma cobertura de $74 \%$, e as Isapre, $18 \%{ }^{12}$. Detectaram-se altos níveis de segmentação por gasto esperado e rendas, pois a população com maiores necessidades de saúde tende a se concentrar no Fonasa ${ }^{13}$. No decil 1, o Fonasa e as Isapre tiveram uma cobertura de $93 \%$ e $2 \%$, respectivamente ${ }^{14}$.

O Gasto Total com Saúde (GTS), em 2015, foi de USD $\$ 1.903$ per capita ${ }^{15}$. Comparado com a América Latina, esse nível de gasto deixa o Chile entre os países com mais altas despesas em saúde ${ }^{16}$. Entretanto, o mesmo patamar mostra-se baixo ao compará-lo com os níveis dos países pertencentes à Organização para a Cooperação e o Desenvolvimento Econômico (OCDE), e com países que possuem sistemas universais ou baseados em seguros ${ }^{\mathbf{1 7}}$.

Em 2014, apenas o financiamento público para saúde foi estimado em 3,9\% do Produto Interno Bruto (PIB) ${ }^{\mathbf{1 8}}$. Como consequência do baixo gasto público, o Chile apresenta altos níveis de desembolso direto com saúde, inclusive, próximos a $40 \%$ do GTS, sendo uma modalidade de gasto não equitativo, não solidária e fortemente empobrecedora ${ }^{19}$.

Desse modo, o sistema de saúde chileno se constitui em um seguro público que cobre a população mais vulnerável, com um baixo gasto per capita, e um conjunto de seguros privados que atinge os segmentos mais favorecidos com um gasto per capita mais alto. Este modelo gera múltiplas iniquidades, além de todas as desvantagens dos sistemas de saúde baseados em seguros. Entretanto, esta conformação público-privada do sistema é o resultado de um longo desenvolvimento histórico das instituições e das políticas de saúde, não ausente de tendências e contratendências. Conhecer esses processos históricos poderá iluminar os padrões de atuação do Estado e de 
grupos de poder que constrangem sociedades com institucionalidades e sistemas de direito debilitados, como as da América do Sul. Deste modo, o objetivo do presente artigo é analisar a trajetória histórica do sistema de saúde chileno e suas políticas de saúde, entre 1924 e 2005.

\section{Material e métodos}

Segundo Batista e Mattos ${ }^{20}$, a análise das políticas sociais busca compreender as dinâmicas de poder entre os grupos sociais que direcionam a ação do Estado em um determinado sentido, fixando a atenção nos atores envolvidos e em sua capacidade de influência; o contexto sociopolítico das mudanças; o cenário onde foram desenvolvidas as discussões; e o conteúdo das regulamentações que materializaram as transformações.

Este estudo faz parte de um projeto maior, focado no esquema de financiamento da atenção primária, no Chile. Tendo em vista esse propósito, foi necessário conhecer a estrutura atual do sistema de saúde, especialmente quanto à participação dos setores público e privado, assim como sua trajetória histórica. Sendo assim, o estudo empregou a revisão integrativa de literatura como método de obtenção das informações. Para Gil21 , a pesquisa bibliográfica é necessária para a delimitação da investigação, e é sugerida nos estudos históricos. Procura resultados exploratórios, que sugerem linhas e questões a serem aprofundadas em outros estudos; tem abrangência e amplitude, pois permite a inclusão de temáticas ou fenômenos dispersos no tempo e no espaço; e emprega material já elaborado e publicado.

Na pesquisa, foram analisados resultados de investigações científicas, como livros, capítulos de livros, teses de doutorado e artigos. Também foram consultadas as legislações relacionadas às transformações da institucionalidade em saúde publicadas no site do Congreso Nacional de Chile. O material bibliográfico foi categorizado por ano, tipo e conteúdo, e a análise foi orientada para o desvendamento das relações entre: o público e o privado; a conjuntura política; os modelos de financiamento; os instrumentos legais importantes (legislação); o papel do Estado; as concepções de saúde vigentes; e os principais atores envolvidos.

\section{Resultados e discussão}

As mudanças da institucionalidade sanitária no Chile compõem-se de momentos que marcam progressos e retrocessos na garantia do direito à saúde pelo Estado. Certamente, o sistema de saúde chileno pode ser considerado uma síntese de diferentes reformas que foram modelando a institucionalidade, desde, pelo menos, o início do século XX. Segundo a proposição de Labra ${ }^{22}$, trata-se de conjunturas de decisões que implicaram mudanças de natureza estrutural no sistema de saúde, constituídas a partir da influência dos modelos internacionais, das particularidades do contexto sociopolítico do país, e da orientação tomada pelos atores-chave. Por sua vez, as fontes do financiamento, a dinâmica dos serviços assistenciais e o arcabouço jurídico-institucional foram algumas das dimensões dessas mudanças.

Na história do sistema de saúde chileno podem ser descritos vários períodos ${ }^{22-27}$ (quadro 1). O momento fundacional para a organização da institucionalidade do setor saúde inicia-se nas primeiras décadas do século XX. De acordo com as observações de Zárate ${ }^{26}$, este período caracteriza-se por concentrar um debate conceitual quanto ao entendimento da saúde; por um lado, existia uma concepção da saúde como uma questão limitada ao âmbito privado-liberal; por outro, pensava-se a saúde como um problema eminentemente público-coletivo. Esta última ideia é a que foi progressivamente se impondo, modificando o papel do Estado nessa matéria. 
Quadro 1. Principais transformações do sistema de saúde chileno (1924-1989)

\begin{tabular}{|c|c|c|c|c|c|c|}
\hline \multirow{2}{*}{$\begin{array}{l}\text { Transformação } \\
\text { estrutural }\end{array}$} & \multicolumn{6}{|c|}{ Características das transformações estruturais do sistema de saúde chileno } \\
\hline & Descrição & Cobertura & Financiamento & Prestação & Gestão & Regulação \\
\hline $\begin{array}{l}\text { Caixa do Seguro } \\
\text { Social (1924) }\end{array}$ & $\begin{array}{l}\text { Primeiro seguro } \\
\text { social de caráter } \\
\text { compulsório. Ofe- } \\
\text { receu proteção } \\
\text { contra doença, } \\
\text { velhice e morte. }\end{array}$ & $\begin{array}{l}\text { Restrita à popu- } \\
\text { lação operária, } \\
\text { excluindo empre- } \\
\text { gados públicos e } \\
\text { privados. }\end{array}$ & $\begin{array}{l}\text { Considerou aportes } \\
\text { tríplices do Estado, } \\
\text { trabalhadores e } \\
\text { empregadores. }\end{array}$ & $\begin{array}{l}\text { Hospitais das } \\
\text { instituições da } \\
\text { beneficência e } \\
\text { dispositivos de } \\
\text { atenção ambulato- } \\
\text { rial próprios. }\end{array}$ & $\begin{array}{l}\text { Foi administrada } \\
\text { pela direção da } \\
\text { Caixa, que tinha } \\
\text { representantes } \\
\text { dos trabalhadores, } \\
\text { empregadores e do } \\
\text { governo. }\end{array}$ & $\begin{array}{l}\text { Ficou encarregada } \\
\text { ao Ministério da } \\
\text { Previdência, que } \\
\text { elaborava a nor- } \\
\text { mativa quanto à } \\
\text { entrega dos bene- } \\
\text { fícios. }\end{array}$ \\
\hline $\begin{array}{l}\text { Serviço Nacional } \\
\text { de Saúde (1952) }\end{array}$ & 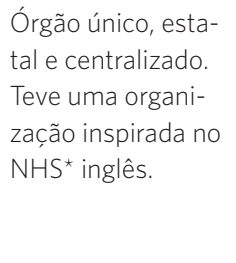 & $\begin{array}{l}\text { Originalmente, } \\
\text { foi restrita aos } \\
\text { assalariados. Pro- } \\
\text { gressivamente, } \\
\text { incorporaram-se } \\
\text { desempregados e } \\
\text { camadas médias. }\end{array}$ & $\begin{array}{l}\text { Manteve os } \\
\text { aportes tríplices, } \\
\text { adicionando o } \\
\text { financiamento das } \\
\text { organizações da } \\
\text { beneficência. }\end{array}$ & $\begin{array}{l}\text { Rede pública na- } \\
\text { cional de hospitais } \\
\text { e centros de aten- } \\
\text { ção primária. Ên- } \\
\text { fase na prevenção } \\
\text { da saúde materno- } \\
\text {-infantil. }\end{array}$ & $\begin{array}{l}\text { Exercida pelo } \\
\text { diretor do SNS, em } \\
\text { cooperação de um } \\
\text { Conselho Assessor. }\end{array}$ & $\begin{array}{l}\text { Feita de modo débil } \\
\text { pelo Ministério da } \\
\text { Saúde, de forma } \\
\text { independentemen- } \\
\text { te do SNS. }\end{array}$ \\
\hline $\begin{array}{l}\text { Lei de Medicina } \\
\text { Curativa (1968) }\end{array}$ & $\begin{array}{l}\text { Implantação da } \\
\text { livre eleição com } \\
\text { subsídio do Estado. }\end{array}$ & $\begin{array}{l}\text { Empregados públi- } \\
\text { cos e privados que } \\
\text { não foram incor- } \\
\text { porados ao SNS } \\
\text { desde o início. }\end{array}$ & $\begin{array}{l}\text { Instaurou os co- } \\
\text { pagamentos por } \\
\text { atendimento nas } \\
\text { camadas de mais } \\
\text { alta renda. }\end{array}$ & $\begin{array}{l}\text { Médicos particu- } \\
\text { lares. Destinou-se } \\
\text { a instalações pú- } \\
\text { blicas para aten- } \\
\text { dimento privado. } \\
\text { Ênfase na saúde } \\
\text { curativa. }\end{array}$ & $\begin{array}{l}\text { Política gestada } \\
\text { através de convê- } \\
\text { nios entre o Ser- } \\
\text { mena* e o SNS. }\end{array}$ & $\begin{array}{l}\text { Continuou restrita } \\
\text { no Ministério da } \\
\text { Saúde, indepen- } \\
\text { dentemente do } \\
\text { SNS. }\end{array}$ \\
\hline $\begin{array}{l}\text { Reformas introdu- } \\
\text { zidas pela ditadura } \\
\text { (1973-1989) }\end{array}$ & $\begin{array}{l}\text { Divisão do antigo } \\
\text { SNS. Criação das } \\
\text { Isapre e do Fonasa, } \\
\text { além de outros } \\
\text { órgãos auxiliares. }\end{array}$ & $\begin{array}{l}\text { Segregação das } \\
\text { pessoas assegura- } \\
\text { das, entre o setor } \\
\text { público (Fonasa) e } \\
\text { o privado (Isapre). }\end{array}$ & $\begin{array}{l}\text { Diminuição do } \\
\text { aporte do fisco e } \\
\text { aumento do aporte } \\
\text { das pessoas. }\end{array}$ & $\begin{array}{l}\text { Prestadores priva- } \\
\text { dos conveniados } \\
\text { às Isapre. Descen- } \\
\text { tralização e muni- } \\
\text { cipalização da rede } \\
\text { pública. }\end{array}$ & $\begin{array}{l}\text { Restrita no Mi- } \\
\text { nistério da Saúde, } \\
\text { desempenhando o } \\
\text { rol de 'ente reitor'. }\end{array}$ & $\begin{array}{l}\text { Exercida por vá- } \\
\text { rios organismos } \\
\text { do Ministério da } \\
\text { Saúde, para o setor } \\
\text { público e privado. }\end{array}$ \\
\hline
\end{tabular}

Fonte: Elaboração própria.

${ }^{*} \mathrm{NHS}=$ National Health Service; Sermena = Servicio Médico Nacional.

Assim, durante a segunda década do século passado, aprovaram-se as chamadas 'leis sociais', mediante as quais o Estado assumiu o papel de protagonista na proteção da saúde, tarefa que, até então, era desenvolvida pelas instituições de caridade, a beneficência e a igreja católica. Entre estas leis, encontra-se a Ley del Seguro Obligatório de Enfermedad y Vejez, que esteve dirigida à população assalariada e criou a Caja del Seguro para cobrir os riscos de doença, morte e aposentadorias. Considerou-se um financiamento tríplice entre trabalhadores, empregadores e o Estado, sendo a distribuição dos aportes a seguinte: operários, $2 \%$; empregadores, $4 \%$; e Estado, $1,5 \%{ }^{28}$.

Em relação à prestação dos serviços, foram estabelecidos convênios com a beneficência e criaram-se dispositivos de atenção ambulatória de propriedade da caixa. Esses dispositivos conformaram as bases da atenção primária, pois consideraram serviços de promoção em saúde e a inclusão do trabalho intersetorial com apoio de visitadoras sociais em contato direto com os moradores das favelas ${ }^{29}$. A gestão da Caja del Seguro era feita de modo autônomo, em uma direção conformada por representantes dos trabalhadores, empregadores e governo. Por sua vez, a cobertura ficou restrita à população assalariada, geralmente operários e suas famílias, chegando a cobrir $80 \%$ dos assegurados nos anos $1940^{30}$. Os trabalhadores das classes médias, também chamados de empregados, contribuíam para outras caixas.

Várias são as hipóteses que tentam explicar o surgimento das legislações sociais, já no início do século XX. Para Massardo ${ }^{31}$, existiu 
uma preocupação, de uma parte importante da elite governante, de se antepor a uma eventual revolução dos setores populares, que se haviam convertido em um ator com consciência histórica e projeto político formado em torno das mutuales e sociedades de ayuda mútua. Tal argumento é concordante com a análise feita por Illanes ${ }^{23}$, que descreve a conformação de um 'Estado guardião', fortemente repressivo e autoritário, e, ao mesmo tempo, acompanhado de um 'Estado assistencial', que começa a outorgar determinadas condições mínimas à população, sendo um projeto incorporacionista. Naquela polaridade, o Estado conteve o conflito social, tentando substituir as organizações tecidas pelo movimento popular e gerando as condições para o avanço do capitalismo, vistas as precárias condições de vida da população e os críticos indicadores sanitários.

Quase três décadas após a criação da Caja del Seguro Social, em 1952, implantou-se o Servicio Nacional de Salud (SNS), política longamente discutida e sujeita às mudanças na correlação de forças das coalizões governantes. O novo órgão foi "encarregado da proteção da saúde, através de ações sanitárias e de assistência social, e de atenções médicas preventivas e curativas"32. Nele, se agruparam as organizações que, até então, concediam atenção médica à população ou guiavam as políticas sanitárias em matéria de higiene pública, as quais tinham funções e atribuições diversas.

Tratou-se de um órgão público, centralizado, integral, com comando técnico único e com uma organização territorial nacional, sendo independente do Ministerio de Salud (Minsal) ${ }^{33}$. A direção nacional do SNS foi colocada na figura do diretor geral, em colaboração com um conselho assessor, que teve como obrigações as mesmas que já estavam presentes isoladamente em cada uma das instituições que foram unificadas. O esquema de financiamento tríplice foi mantido entre empregadores, empregados e o Estado. Quanto à cobertura, se bem formalmente continuou restrita aos setores assalariados de baixa renda, indigentes e aposentados também acessavam ao SNS. Nos anos 1960, estabeleceu-se que $70 \%$ da população recebiam serviços curativos do SNS, enquanto as ações preventivas e atenções de urgência atingiam $100 \%$ da população ${ }^{34}$.

Da interpretação que faz Molina ${ }^{33}$, do processo político que precedeu a criação do SNS, depreende-se que houve dissensos explícitos quanto à orientação que deveria ter a institucionalidade. A discussão esteve submetida a: 1) um projeto conservador, que colocava ênfase nas ações curativas em saúde apenas para a força laboral; 2) um projeto socialista, que advogava pela intervenção do Estado na determinação socioeconômica da saúde; e, finalmente, 3) uma postura orientada pelos princípios da Organização Internacional do Trabalho (OIT), que apelava pelo fortalecimento da institucionalidade sanitária apenas para os trabalhadores formais.

No entanto, os princípios da medicina social universalizada orientaram fortemente a estrutura e gestão do SNS. Eles foram: integralidade das ações, incluindo todas as etapas do ciclo de vida e seus determinantes; planejamento baseado em objetivos e metas; concentração nas etapas mais vulneráveis da vida; comando único das ações de saúde, públicas e privadas, dirigidas pela autoridade técnica superior; obrigação do Estado de prover os recursos necessários para ações integradas de saúde ${ }^{35}$. Apesar do peso desses fundamentos, a correlação de forças políticas e sociais de então só permitiu mudanças graduais e negociadas sob a hegemonia dos setores conservadores.

Contudo, a criação do SNS foi a realização mais importante na história da saúde pública do país, já que se tratou de uma instituição estatal e centralizada, que aumentou a cobertura das atenções médicas, instalando uma lógica de planificação sanitária com priorização da saúde materno-infantil, e implantando uma rede pública que chegou até os lugares rurais mais distantes do país, com presença de clínicos gerais responsáveis pelo território ${ }^{36-38}$. Entre os êxitos relacionados à instauração do SNS, encontram-se o forte descenso da mortalidade infantil, que caiu de $132 /$ mil nascidos 
vivos, em 1950, para 31/mil nascidos vivos, em 1980; o incremento da esperança de vida, que aumentou de 53-56 anos, em 1950, para 67-74 anos, em 1980; o controle da tuberculose e a erradicação da poliomielite ${ }^{34}$.

De acordo com Merino ${ }^{27}$, o período entre 1960-1973 caracteriza-se pela democratização da saúde a partir das bases populares da sociedade, entre movimentos sociais de moradores, trabalhadores, estudantes e alguns segmentos dos profissionais da saúde, processo que teve materialização em várias políticas desenvolvidas em torno do SNS. Exemplo disso foi o Programa Médicos Generales de Zona, que lotou profissionais recém-formados nas localidades rurais mais afastadas do país e nos bairros das periferias das cidades, impulsando fortemente o trabalho intersetorial em saúde e a participação comunitária, gerando iniciativas baseadas na educação para saúde e serviços preventivos e promocionais. $\mathrm{Na}$ prática, esse Programa constituiu um espaço privilegiado para o exercício profissional de um grupo importante de médicos que consideravam a prática médica enquanto prática emancipatória.

Um terceiro momento da conjuntura de mudança estrutural em saúde foi a ley de medicina curativa, de 1968. Essa legislação regulamentou e permitiu a atenção médica e dental dos funcionários públicos e suas famílias, em infraestrutura hospitalar pertencente ao SNS22. Além disso, incorporou a livre eleição em saúde, pois os empregados públicos - na época, os setores médios - tinham direito a escolher o profissional, segundo suas preferências. $\mathrm{E}$ também foram permitidos copagamentos por ato médico aos profissionais. A lei facultou ao SNS assinar convênios nos quais se regulamentavam as condições para a utilização dos estabelecimentos e equipamentos públicos dirigidos à atenção privada dos empregados.

Segundo Molina ${ }^{39}$, no processo dessa lei, exerceram especial importância as posições e os interesses da profissão médica e das camadas médias da população, os primeiros interessados em desenvolver um mercado de trabalho privado e os segundos a acessar, em condições preferenciais, aos serviços de atendimento público. Alguns dos principais efeitos dessa legislação foram uma atenção discriminatória entre assalariados e empregados, a preponderância do enfoque curativo e a consolidação dos médicos como principais atores da política de saúde ${ }^{40}$. De acordo com o autor, essa lei, ao permitir o pagamento por ato médico e a livre eleição com subsídio do Estado, promoveu o ingresso do capital no campo da saúde, sendo contrária à ideia de universalização.

O último momento de mudança estrutural em saúde correspondeu às reformas introduzidas pela ditadura, entre os anos de 1973 e 198922. Entre outros pontos, a ditadura de Pinochet diluiu o projeto de Estado formado pelos setores populares, mediante a dissolução violenta de partidos políticos, sindicatos, federações de estudantes e agrupamentos populares ${ }^{41}$. Segundo Garretón e Malva ${ }^{42}$, a ditadura diminuiu a capacidade redistributiva do Estado, ampliou seu caráter coercitivo e implementou mecanismos de mercado na sociedade civil.

Após o golpe militar, observou-se um brusco declínio do gasto social, tendência replicada em outros países do continente, em consequência do Consenso de Washington, que apelava por uma ampliação da esfera do mercado na economia ${ }^{43}$. Um exemplo paradigmático do recorte fiscal se refere aos recursos destinados à saúde. Dos dados entregues pelo economista Patricio Meller ${ }^{44}$, depreende-se que, entre 1974 e 1987, a média de gastos social por pessoa foi $71 \%$ do observado em 1970. Outras informações referenciadas por Labra ${ }^{45}$ indicam que o fisco passou de representar $68 \%$ dos gastos em saúde para $35 \%$, enquanto os copagamentos aumentaram de $10 \%$ para $50 \%$.

A diminuição do orçamento público para a saúde foi feita paralelamente a uma reestruturação administrativa ${ }^{46}$. Mediante o DecretoLei $\mathrm{n}^{\circ} 2.763$, limitaram-se as atribuições do Minsal à fiscalização; a execução da atenção foi colocada no SNSS, novo órgão que fornecia 
atenção de forma descentralizada em 27 serviços de saúde autônomos; estabeleceu-se a criação do Fonasa para arrecadar as contribuições sociais dos afiliados do seguro público; e também se criaram vários órgãos auxiliares ${ }^{47}$.

Posteriormente, no Decreto-Lei $n^{0}$ 1-3.063, municipalizou-se a administração da atenção primária, gerando uma deterioração da dotação e operação dessas unidades e desarticulando o trabalho em rede das unidades públicas de saúde ${ }^{48}$. Logo a seguir, no mesmo ano, implantaram-se as Isapre, que têm até hoje uma finalidade lucrativa ${ }^{\mathbf{4 9}}$.

Em síntese, estratificou-se a atenção à saúde do seguinte modo: as pessoas que tinham os maiores salários, que puderam comprar seus planos de saúde no mercado das Isapre; os setores médios, que puderam optar pela modalidade de livre escolha do Fonasa para o atendimento com prestadores privados, fazendo copagamentos; e os setores com os salários mais baixos, ou desempregados, que eram atendidos nas unidades de saúde do Estado gratuitamente quando comprovada a condição de pobreza 45 .

De acordo com o trabalho de Tetelboin ${ }^{50}$, as reformas introduzidas pela ditadura orientaram-se para a conversão neoliberal do sistema de saúde chileno em três dimensões: regulação, financiamento e operação dos serviços. Primeiro, a regionalização e municipalização da atenção primária tiveram como objetivo o controle político dos trabalhadores e a introdução de concessões ao setor privado, questão que não teria sido possível com o antigo sistema público. Segundo, as tendências no financiamento apontaram o aumento do desembolso direto e a diminuição dos recursos do Estado, aspectos que influíram no subfinanciamento do setor saúde. Por último, as reformas conformaram um sistema de atenção com uma lógica individualista e mercantilizada. Ou seja, no contexto autoritário imposto pela ditadura de Pinochet, as reformas foram dirigidas sem maiores resistências para o neoliberalismo, originando um sistema de orientação privatista e destruindo as instituições públicas existentes até então. Diferentemente, no Brasil, naquela época, vivia-se um processo de redemocratização, com forte participação do Movimento pela Reforma Sanitária, contribuindo com a implementação de um sistema estatal, que integrou ao SUS as instituições encarregadas, tanto da saúde previdenciária quanto das ações sanitárias coletivas ${ }^{51}$.

As repercussões da privatização do sistema de saúde chileno são resumidas do modo a seguir: maior complexidade administrativa do sistema; grandes dificuldades administrativas de regulação das Isapre, pois oferecem inúmeros planos de saúde diferentes; aumento desorganizado dos custos; subfinanciamento da saúde destinada aos pobres; desaparecimento do conceito de solidariedade; e fortes diferenças entre os serviços oferecidos pelos municípios, pois os mais ricos fornecem atenções de maior qualidade ${ }^{52}$. A crise financeira foi desencadeada pela instauração das Isapre, que nos anos 1990 administravam 45\% dos recursos, enquanto só atendiam $27 \%$ da população nacional53. Em 2000, as Isapre tinham uma cobertura de $25 \%$ e recebiam $69 \%$ dos recursos das contribuições sociais, enquanto o Fonasa ficava com $31 \%$ dos recursos, atendendo $64 \%$ da população $0^{54}$.

Esses efeitos negativos da privatização do sistema de saúde chileno são similares aos encontrados em outros países. No caso da Colômbia, a privatização da saúde levou falência a hospitais públicos, ao Seguro Social; à judicialização da saúde; à falta de regulação, por parte do Estado, sobre as empresas seguradoras, pois as agências reguladoras não têm os recursos nem o poder para controlar as empresas privadas; $\mathrm{e}$ a crise financeira permanente do setor ${ }^{55,56}$.

Alguns dos esforços durante os governos, após a ditadura, foram: o aumento da inversão para infraestrutura pública da rede hospitalar; o apoio aos programas de saúde dos municípios prioritários; e a modernização administrativa das instituições públicas ${ }^{54}$. No entanto, a constatação das desigualdades nos indicadores sanitários entre a população assegurada pelo 
Fonasa e pelas Isapre, assim como também entre os próprios filiados ao Fonasa, tornou cada vez mais necessária uma nova reforma ${ }^{57}$.

Essa reforma foi postergada até o governo do ex-presidente Ricardo Lagos Escobar (2000-2006), principalmente pela falta de consenso político da coalizão de governo ${ }^{58}$. Foi conhecida como Acceso Universal con Garantías Explícitas (Auge) e, posteriormente, como Garantías Explicitas en Salud (GES), e foi concretizada por meio de cinco leis. Um primeiro avanço foi o estabelecimento dos Objetivos Sanitarios para la Década 20002010, entre os quais se podem citar: melhorar os resultados sanitários obtidos; enfrentar os desafios derivados do envelhecimento da população e das mudanças na sociedade; enfrentar as iniquidades em saúde; e prestar serviços de saúde em função das expectativas da população $0^{59}$.

A primeira lei, quanto ao financiamento, aumentou de $18 \%$ apara $19 \%$ o Impuesto al Valor Agregado (IVA), além de incrementar impostos à comercialização e ao consumo de tabaco, com a finalidade de aumentar a arrecadação dos recursos estatais ${ }^{60}$.

A segunda lei modificou a estrutura organizacional do setor, consolidando o Minsal como 'ente reitor' e dividindo-o entre a Subsecretaría de Redes Asistenciales e a Subsecretaría de Salud Pública ${ }^{61}$.

A terceira lei é a mais importante das legislações consideradas por essa reforma. Gerou um Régimen General de Garantías en Salud, no qual se contemplaram as GES para um grupo restrito de problemas de saúde. Na normativa, tais garantias correspondem a direitos assegurados aos usuários, tanto do Fonasa quanto das Isapre, que podem ser exigidos legalmente. Especificaram-se quatro tipos de garantias: de acesso, qualidade, proteção financeira e oportunidade ${ }^{62}$. Esta última estabelece prazos máximos para que os usuários recebam os serviços. A implementação das GES começou, em abril de 2005, com 25 problemas de saúde garantidos $^{63}$. Na atualidade, se contabilizam 80 condições.
A quarta lei regulamentou o mercado das Isapre e incorporou uma tabela de fatores de risco para o estabelecimento dos preços dos planos oferecidos, que devem ser informados aos usuários; também se incluiu, para essas instituições, a obrigatoriedade de fornecer informação financeira à Superintendencia de Salud (SIS)64. A última legislação promulgada especificou os direitos e deveres das pessoas em relação à atenção da saúde, como a companhia e assistência espiritual, a informação do estado de saúde, entre outros ${ }^{65}$.

Basicamente, a Reforma de Saúde AugeGES instaurou a lógica da priorização em saúde ${ }^{66}$, mas em uma perspectiva não integral e restritiva. No Brasil, por exemplo, a priorização não exclui o atendimento a outras condições, como no Chile. Não existe consenso a respeito da contribuição desta reforma para a equidade em saúde. Um dos aspectos destacados é a fixação de copagamentos máximos, de acordo com o nível de renda das pessoas ${ }^{67}$. No entanto, o desembolso direto em saúde como proporção dos gastos das famílias continua alto ${ }^{68}$. Um dos efeitos negativos foi o incremento das listas de espera de pacientes 'não Auge', quem têm seu atendimento postergado, pois os prestadores possuem incentivos para a resolução das 80 condições garantidas ${ }^{69}$.

Segundo Olavarría ${ }^{70}$, a discussão parlamentar da Reforma de Saúde Auge-GES foi negociada por três setores políticos: a 'posição estatista', a 'privatista' e a 'saúde regulada'. A dinâmica de negociação entre esses grupos fez com que não se concretizassem transformações estruturais no sistema de saúde. Tal constatação é concordante com as observações de Mayol71, que estudou a conformação da Nueva Mayoría, coalizão de centro-esquerda que governou entre 2014 e 2017, e que emergiu da antiga Concertación de Partidos por la Democracia, junto ao Partido Comunista Chileno. Para o autor, as duas coalizões, tendo um discurso progressista, acabaram cedendo o conteúdo das políticas sociais para a direita política e econômica. Esses acordos se expressaram na não concretização de um fundo solidário, entre 
as leis aprovadas, apesar de ter sido longamente discutido durante a tramitação parlamentar. Esse órgão administraria, conjuntamente, uma seção das contribuições sociais dos filiados aos dois setores (Fonasa e Isapre).

O projeto de um fundo solidário foi rejeitado pela influência do setor privado, pela divisão da coalizão de governo e pela ausência de mobilização social72. Deve ser destacado que o contexto sociopolítico da época não foi favorável a políticas que resguardassem direitos sociais, apesar de existirem governos apoiados em coalizões ditas de centro-esquerda. Segundo Moulian $^{73}$, o Chile da época caracterizou-se pelo 'transformismo' do modelo neoliberal imposto, que, tendo em vista a legitimidade do capital financeiro internacional, precisava se consolidar em um sistema de 'democracia protegida' que garantisse a continuidade do projeto, especialmente no tocante à defesa do livre mercado, à desregulação da economia e do mercado de trabalho, e ao resguardo irrestrito da propriedade privada.

O último espaço institucional de discussão foi a Comisión Asesora Presidencial para el Estudio y Propuesta de un Nuevo Marco Jurídico para el Sistema Privado de Salud, durante o segundo governo da ex-presidente Michelle Bachelet. Propôs-se a implantação de um fundo único, administrado por um seguro nacional de saúde, cuja missão seria coletar e administrar os recursos das diferentes fontes, incluindo as contribuições sociais dos filiados às Isapre. Na prática, o governo não materializou a proposta, sendo evidente o peso dos interesses do mundo privado nesta decisão.

Uma das críticas à reforma aponta a sua indecisão entre manter um sistema de seguros ou reforçar o setor público. Para Tetelboin ${ }^{74}$, isto constitui o núcleo do que veio a chamar 'reformas neoliberais de segunda geração', que reconfiguram a relação público-privada ao facilitarem a compra de serviços junto ao setor privado, com fundos públicos. Certamente, ao garantir a resolução de um grupo limitado de doenças sem uma transformação estrutural do sistema, a Reforma de Saúde Auge-GES sobrecarregou o setor público e o impeliu à compra de serviços ${ }^{75}$. Outros questionamentos se dirigem à implantação de uma cesta básica de prestações garantidas pelas GES; aos incentivos perversos da autogestão hospitalar; e à manutenção da segregação por risco no mercado das Isapre ${ }^{76}$.

Por outro lado, as GES não interferem no processo de adoecimento e ainda prejudicam a integração do cuidado ao diferenciarem doenças 'Auge' de doenças 'não Auge'77. Outros autores apontaram uma focalização dos serviços apenas nas doenças inclusas, através de instrumentos de gestão orientados ao cumprimento de metas que desconsideram a promoção da saúde e prevenção de agravos ${ }^{78}$.

\section{Conclusões}

As reformas neoliberais produziram mudanças no SNS chileno, que se tornou dividido em um subsistema público (Fonasa), organizado em uma modalidade de solidariedade social, mas, cujo acesso aos serviços se restringe a um 'menu' com apenas 80 condições de saúde; e outro privado (Isapre), conduzido por uma lógica curativa e individual, e sem o respaldo de uma atenção primária. Os processos que conduziram à dualidade do sistema de saúde do Chile não apenas reproduzem as desigualdades sociais do conjunto social, como as ampliam, resultando na manutenção de altos índices de desembolso direto, o que contribui para a insegurança e desproteção de ambas as populações, mas, certamente, com maior impacto nos setores menos favorecidos.

A Reforma de Saúde Auge-GES, ao implantar cestas básicas de serviços e a autogestão hospitalar, tem incentivado o risco moral por meio da segregação de clientelas e patologias, comprometendo a integralidade e a equidade dos serviços. Essas reformas tentaram modificar alguns aspectos do sistema, mas não alteraram sua estrutura básica. O impacto da privatização do sistema mostra-se não apenas na continuidade da sua dualidade, mas também 
no conteúdo das poucas instâncias de transformação que têm existido depois de 1989, pois a discussão tem estado restrita à qualidade dos seguros que administram as contribuições sociais. Deste modo, a construção de um sistema universal de saúde, financiado através da arrecadação do Estado, destinado a toda a população, sem restrições, tem estado totalmente ausente.

As dinâmicas de reorganização do capital têm penetrado cada vez mais fortemente no âmbito da seguridade social, restringindo as esferas do direito coletivo, transformando cidadãos em consumidores e não consumidores. Tal radicalidade do processo privatizador tem atingindo também os governos ditos progressistas, que terminam cedendo às pressões do capital econômico para manterem o capital político, pelo menos, em curto prazo.

A experiência chilena funciona como um espelho temporal invertido, que aponta para desenlaces indesejados, no caso do Brasil. Tais desenlaces, ao comprometerem profundamente a universalidade estabelecida constitucionalmente, precisam ser, a todo custo, explicitados, analisados e compreendidos nos seus mecanismos, tanto estruturais quanto fenomênicos, de forma a orientar estratégias de resistência e combate, enquanto ainda é possível.

\section{Colaboradores}

Cortés FAM (0000-0001-6207-5882)*, Coelho TCB (0000-0003-4787-4103)* e Sanabria CAP (0000-0002-4686-2197)* contribuíram igualmente para a concepção e o planejamento; para a análise e a interpretação dos dados; para a elaboração do rascunho e revisão crítica do conteúdo; e para a aprovação da versão final do manuscrito.

\section{Referências}

1. Almeida C. Reformas de sistemas de saúde: tendências internacionais, modelos e resultados. In: Giovanella L, Escorel S, Lobato LVC, et al. Políticas e sistemas de saúde no Brasil. Rio de Janeiro: Fiocruz; 2012. p. $759-803$.

2. Laurell A. La lógica de la privatización en salud. In: Eibenschutz C. Política de Saúde, o público e o privado. Rio de Janeiro: Fiocruz; 1995. p. 31-48.
3. Almeida C. Reforma de sistemas de servicios de salud y equidad en América Latina y el Caribe: algunas lecciones de los años 80 y 90. Cad. Saúde Pública. 2002; 18 (4):905-925.

4. Fleury S. ¿¿Universal, dual o plural? Modelos y dilemas de atención de la salud en América Latina: Chile, Brasil y Colombia. In: Molina C, Núñez J. Servicios de Salud en América Latina y Asia. Washington D.C.: BID; 2003. p. 3-40.
*Orcid (Open Researcher and Contributor ID). 
5. Larrañaga O. Eficiencia y equidad en el sistema de salud chileno. In: Titelman D, Uthoff A. Ensayos sobre el financiamiento de la seguridad social en salud. Los casos de Estados Unidos, Canadá, Argentina, Chile y Colombia. Santiago de Chile: Fondo de Cultura Económica; 2000. p. 415-461.

6. Parada M, Ibacache $\mathrm{C}$, Medina S, et al. Informe de Salud en Chile. In: González R, Barria S, Sengupta A. La lucha por el derecho a la salud en América Latina. El Salvador: ALAMES; 2014. p. 31-51.

7. Goyenechea M. Análisis del presupuesto en salud en el contexto de la desigualdad en Chile. Medwave. $2011 ; 11(12): 1-5$.

8. Becerril-Montekio V, Reyes J, Manuel A. El sistema de salud de Chile. Salud pública Méx. 2011; 53(2):3243.

9. Urriola R. Financiamiento de la atención de salud en Chile. Cuad. Médico Soc. 2010; 50(2):83-94.

10. Chile. Ministerio de Salud. Más salud, mejora tu vida. 2018. [acesso em 2018 jan 12]. Disponível em: https:// www.camara.cl/trabajamos/comision_listadodocumento.aspx?prmID=411.

11. Cid C, Muñoz A, Riesco X, et al. Equidad en el financiamiento de la salud y protección financiera en Chile: una descripción general. Cuad. Med. Soc. 2006; 46 (1):5-12.

12. Fundo Nacional de Saúde. Boletín Estadístico 20152016. 2017. [acesso em 2017 set 1]. Disponível em: https://www.fonasa.cl/sites/fonasa/institucional/ archivos\#documentos-estadisticos-institucionales.

13. Vergara-Iturriaga M, Martínez-Gutiérrez M. Financiamiento del sistema de salud chileno. Salud Pública Méx. 2006; 48(6):512-521.

14. Chile. Ministerio de Desarrollo. CASEN 2015. Salud, síntesis de resultados. 2016. [acesso em 2017 set 21]. Disponível em: http://observatorio.ministeriodesarrollosocial.gob.cl/casen-multidimensional/casen/ docs/CASEN_2015_Resultados_salud.pdf.
15. World Health Organization. Global Health Observatory. 2014. [acesso em 2017 set 12]. Disponível em: http://apps.who.int/gho/data/view.main. HEALTHEXPRATIOPER?lang=en.

16. Piola S. La financiación de la salud en los países seleccionados de América Latina. In: Rodríguez V, organizador. Observatorio Internacional de Capacidades Humanas, Desarrollo y Políticas Públicas. Brasília, DF: UnB; Fiocruz-Nethis; 2013. p. 191-211.

17. Organização para a Cooperação e Desenvolvimento Econômico. Heath et a Glance. 2017. [acesso em 2017 out 18]. Disponível em: http://www.oecdilibrary.org/ docserver/download/8117301e.pdf? expires $=1511050$ 037\&id=id\&accname=guest \&checksum $=8488 \mathrm{~B} 1 \mathrm{C} 27$ 0A58E20F9047FC995F52168.

18. Cid C, Matus-López M, Báscolo E. Espacio fiscal para la salud en las Américas: ¿̨es suficiente el crecimiento económico? Rev. Panam. Salud Pública. 2018; 42(86):1-7.

19. World Health Organization. World Health Statistics 2016. Monitoring Health for the SDG. 2016. [acesso em 2017 set 12]. Disponível em: http://www.who.int/ gho/publications/world_health_statistics/en/.

20. Batista T, Mattos R. Sobre política (ou o que achamos pertinente refletir para analisar políticas). In: Mattos R, Batista T. Caminhos para análise das políticas de saúde. Porto Alegre: Rede Unida; 2015. p. 83-149.

21. Gil A. Métodos e técnicas de pesquisa social. São Paulo: Atlas; 2008.

22. Labra M. Política, saúde e interesses médicos no Chile (1900-1990). Ciênc. Saúde Colet. 2001; 6(2): 361376.

23. Illanes M. En el nombre del Pueblo, del Estado y de la Ciencia. Historia social de la salud pública. Chile 1880-1973. Santiago de Chile: Colectivo de Atención Primaria; 1993.

24. Parada M. Evolución del sistema de protección social de la salud en Chile. Un análisis sociológico. [tese]. 
Barcelona: Universitat de Barcelona; 2004. [acesso em 2020 maio 28]. Disponível em: https://core.ac.uk/ download/pdf/19577113.pdf.

25. Molina C. Institucionalidad sanitaria chilena 18891989. Santiago de Chile: LOM; 2010.

26. Zárate M. Por la salud del cuerpo, historia y políticas sanitarias en Chile. Santiago de Chile: Ediciones Universidad Alberto Hurtado; 2011.

27. Merino C. Del proyecto interrumpido de la democratización de la salud a la práctica médica neoliberal en Chile. Osorno: Editorial Universidad de Los Lagos; 2016.

28. Chile. Ley del Seguro Social Obligatorio. 1924. [acesso em 2017 ago 21]. Disponível em: https://www.leychile. $\mathrm{cl} /$ Consulta/listaresultadosimple?cadena=ley+4054.

29. Campillay M. ¿̨Salud para todos? La atención primaria de salud en Chile y los 40 años de Alma Ata, 19792018. Santiago de Chile: Ministerio de Salud; 2018.

30. Arellano J. Políticas Sociales y Desarrollo. Santiago de Chile: CIEPLAN; 1985.

31. Massardo J. Extensión del estado en la sociedad civil y protección social de la salud (1865-1924). In: Urbina L. Historia de la protección social de la salud en Chile. Santiago de Chile: LOM; 2009. p. 39-55.

32. Chile. Modifica Ley 4.053 relacionada con el Seguro Obligatorio. 1952. [acesso em 2017 set 12]. Disponível em: https://www.leychile.cl/ Navegar?idNorma $=26387$.

33. Molina C. Antecedentes del Servicio Nacional de Salud. Historia de debates y contradicciones. Chile 1932-1952. Cuad. Med. Soc. 2006; 46(4):284-304.

34. Horwitz A. Servicio Nacional de Salud Pública chilena. In: MINSAL. La salud en el proceso de desarrollo chileno. Santiago de Chile: MINSAL; 1995. p. 63-83.

35. Labra M. Medicina Social en Chile: propuestas y debates (1929-1950). Cuad. Med. Soc. 2004; 44(4):207-219.
36. Jiménez J. Mística, ciencia y política en la construcción de sistemas de salud. La experiencia de Chile. Salud Pública Méx. 2001; 43(5):485-492.

37. Azevedo C. La provisión de servicios de salud en Chile: aspectos históricos, dilemas y perspectivas. Rev. Saúde Pública. 1998; 32(2):192-199.

38. Zárate M, Godoy L. Madres y niños en las políticas del Servicio Nacional de Salud de Chile (1952-1964). Hist. Ciênc. e Saúde-Manguinhos. 2011; 18(1):131-151.

39. Molina C. La Ley de Medicina Curativa. Un análisis histórico de sus antecedentes y efectos en la institucionalidad sanitaria chilena. Parte I. Cuad. Med. Soc. 2006; 46(1):74-100.

40. Molina C. La Ley de Medicina Curativa. Un análisis histórico de sus antecedentes y efectos en la institucionalidad sanitaria chilena. Parte II. Cuad. Med. Soc. 2006; 46(1):74-100.

41. Salazar G. Lo social (popular) y lo político (nacional) en Chile ¿Crisis del modo clientelista de articulación? In: CLACSO. Movimientos sociales y política, el desafío de la democracia en América Latina. Santiago de Chile: CLACSO; 1990. p. 183-197.

42. Garretón M, Malva E. ¿Reformas del estado o cambio de la matriz sociopolítica? Revista Perfiles Latinoamericanos. 1993; 1(1):133-170.

43. Tomassini T, Armijo M. Reforma y modernización del Estado, experiencias y desafíos. Santiago de Chile: LOM; 2002.

44. Meller P. Resultado de cuatro gobiernos chilenos 1958-1989. Santiago de Chile: CIEPLAN; 1990.

45. Labra M. La reinvención neoliberal de la inequidad en Chile: el caso de la salud. Cad. Saúde Pública. 2002; 18(4):1041-1052.

46. Manuel A. The Chilean Health System: 20 Years of Reforms. Salud Pública Méx. 2002; 44(1):60-68.

47. Chile. Decreto Ley 2763. Reorganiza el Ministerio de 
Salud y crea los Servicios de Salud, el Fondo Nacional de Salud, el Instituto de Salud Pública de Chile, y la Central de Abastecimiento del Sistema de Servicios de Salud. 1979. [acesso em 2017 set 23]. Disponível em: https://www.leychile.cl/Navegar?idNorma=6999.

48. Sepúlveda C. El significado histórico de la reforma de la atención de salud en Chile. Cuad. Méd. Soc. 2004; 43(1):21-36.

49. Chile. DFL 3: Fija normas para el otorgamiento de prestaciones y beneficios de salud, por parte de Instituciones de Salud Previsional. 1981. [acesso em 2017 set 12]. Disponível em: https://www.leychile. $\mathrm{cl} /$ Navegar?idNorma $=3570$.

50. Tetelboin C. La transformación neoliberal del sistema de salud. Chile 1973-1990. Ciudad de México: UAM-X; 2003.

51. Labra M. Política de saúde no Chile e no Brasil. Contribuições para uma comparação. Ciênc. Saúde Colet. 2001; 6(2):361-376.

52. Homedes N, Ugalde A. Privatización de los servicios de salud: las experiencias de Chile y Costa Rica. Gac. Sanit. 2002; 16(1):54-62.

53. Tetelboin C, Granados J. Las ISAPRE y su impacto en el sistema de salud chileno. Nueva Época. 1999; 4(7):7-14.

54. Oyarzo C. La descentralización financiera en Chile en la década de los noventa. Rev. Panam. Salud Pública. 2000; 8(1/2):72-82.

55. Prada C, Chavez S. Health system structure and transformations in Colombia between 1990 and 2013: a socio-historical study. Critical Public Health. 2019; 29(3):314-324.

56. Prada C, Chavez S. Options and political stream in the formulation of the Colombian health system (Bill 100). Saúde debate. 2014; 38(100):35-49.

57. Arteaga O. El difícil camino desde el diseño a la implementación de las reformas de salud. Revista chi- lena de salud pública. 2004; 8(1):39-43.

58. Lenz R. Proceso político de la Reforma AUGE de Salud en Chile. Algunas lecciones para América Latina. 2007. [acesso em 2018 jan 21]. Disponível em: http:// www.cieplan.org/media/publicaciones/archivos/154/ Capitulo_1.pdf.

59. Chile. Ministerio de Salud. Objetivos Sanitários 20002010. 2002. [acesso em 2018 jan 12]. Disponível em: http://www.bibliotecaminsal.cl/wp/wp-content/ uploads/2016/03/5.pdf.

60. Chile. Establece financiamiento necesario para asegurar los objetivos sociales prioritarios del gobierno. 2003. [acesso em 2018 jan 12]. Disponível em: https://www.leychile.cl/Navegar?idNorma=213493\&id Parte $=0$.

61. Chile. Modifica el D.L. N².763, de 1979 con la finalidad de establecer una nueva concepción de autoridad sanitaria, distintas modalidades de gestión y fortalecer la participación ciudadana. 2004. [acesso em 2018 jan 21]. Disponível em: https://www.leychile.cl/ Navegar?idNorma $=221629$ \&idParte $=0$.

62. Chile. Ley 19.966. Establece un Régimen de Garantías en Salud. 2004 [acesso em 2018 jan 12]. Disponível em: https://www.leychile.cl/Navegar?idNorm $a=229834 \&$ idParte $=0$.

63. Chile. Aprueba Garantías Explícitas en Salud del Régimen General de Garantías en Salud. 2016. [acesso em 2018 jan 13]. Disponível em: https://www.leychile.cl/ Navegar?idNorma=1088081\&idVersion=2016-07-01.

64. Chile. Ley 20.015. Modifica Ley $N^{\circ} 18.933$, sobre Instituciones de Salud Previsional. 2005. [acesso em 2018 jan 12]. Disponível em: http://www.leychile.cl/Nave gar?idNorma $=238102 \&$ idParte $=0$.

65. Chile. Ley 20.584. Regula los derechos y deberes que tienen las personas en relación con acciones vinculadas a su atención en salud. 2012. [acesso em 12 jan 2018]. Disponível em: https://www.leychile.cl/ Navegar?idNorma $=1039348$. 
66. Erazo Á. Comisión Económica para América Latina y el Caribe. La Protección Social en Chile. El plan AUGE: avances y desafíos. 2011. [acesso em 21 jan 2018]. Disponível em: https://www.cepal.org/es/ publicaciones/5218-la-proteccion-social-chile-plan-auge-avances-desafios.

67. Valdivieso V, Montero J. El plan AUGE: 2005 al 2009. Rev. Med. Chile. 2010; 138(8):1040-1046.

68. Paraje G, Infante A. La Reforma AUGE, diez años después. In: Larrañaga O, Contreras D. Las nuevas políticas de protección social en Chile. Santiago de Chile: Uqbar Editores; 2015. p. 73-112.

69. MINSAL. Plan Extraordinario para la Reducción de Listas de Espera No AUGE. 2015. [acesso em 2018 jan 12]. Disponível em: http://www.minsal.cl/plan-extraordinario-para-la-reduccion-de-listas-de-espera-no-auge/.

70. Olavarría M. ¿̨Cómo cambian las políticas públicas? Análisis de la formulación del Plan AUGE. In: Olavarría M. ¿Cómo se formulan las políticas públicas en Chile? Tomo 2: el Plan AUGE y la reforma de la salud. Santiago de Chile: Editorial Universitaria; 2011. p. 59-99.

71. Mayol A. La Nueva Mayoría y el fantasma de la Concertación. Cambios estructurales o la medida de lo posible. Santiago de Chile: CEIBO; 2014.

72. Parada M. Financiamiento solidario: un espejismo en la reforma sanitaria chilena. Cuad. Méd. Soc. 2005; 45(2):138-143.
73. Moulian T. Chile actual, anatomía de un mito. Santiago de Chile: Ediciones LOM; 2002.

74. Tetelboin C. Sistema de saúde, desenvolvimento e direitos no Chile: uma questão a ser construída. In: Cohn A, organizador. Saúde, cidadania e desenvolvimento. Rio de Janeiro: Centro Internacional Celso Furtado de Políticas para o Desenvolvimento; 2013. p. $185-220$.

75. Tetelboin C. Tendencias y contratendencias en el sistema de salud de Chile en el marco de la situación regional. In: Tetelboin C, Laurell A. Por el derecho universal a la salud, una agenda latinoaericana de análisis y lucha. Ciudad de México: CLACSO; 2015. p. 75-98.

76. Alames. Chile: el derecho a la salud. 2015. [acesso em 2018 jan 14]. Disponível em: http://www.alames.org/ index.php/documentos/libros/medicina-social/informes.

77. Almeida P, Oliveira S, Giovanella L. Integração de rede e coordenação do cuidado: o caso do sistema de saúde do Chile. Ciênc. Saúde Colet. 2018; 23(7):22132228.

78. Parada M, Reyes C, Cuevas K, et al. Transformaciones del sistema de salud público post Reforma AUGE-GES en Valparaíso. Revista chilena de salud pública. 2014; 18(2):127-139.

Recebido em 01/09/2019

Aprovado em 08/04/2020

Conflito de interesses: inexistente

Suporte financeiro: Coordenação de Aperfeiçoamento de Pessoal

de Nível Superior (Capes) 